\title{
Varietal Characteristics of Exotic Plum Cultivars under Changing Climate Scenario of North Western Himalayas
}

\author{
A.S. Sundouri, S.K. Verma, M.K. Sharma, S.A. Simnani, Aroosa Khalil, \\ Nowsheen Nazir and Rafiya Mushtaq* \\ Division of Fruit Science, Sher-e-Kashmir University of Agricultural Sciences and Technology \\ of Kashmir, Jammu and Kashmir, 1900025, India \\ *Corresponding author
}

\begin{tabular}{|l|}
\hline K e y w o r d s \\
Plum, \\
Characteristic, \\
Cultivars, Yield, \\
Climate change
\end{tabular}

\section{Introduction}

Plum is one of the important and widely cultivated stone fruits ranking fourth after apple, pear and peach (Vishnu et al., 2012). It is predominantly grown in temperate and subtemperate regions of different states of India, which provide excellent and congenial climatic conditions for its cultivation. High chill plum is mostly grown in temperate climatic conditions of Jammu and Kashmir and Himachal Pradesh, whereas low chill in sub temperate climatic conditions of Punjab, Uttarakhand, hills of Uttar Pradesh and NER of Sikkim and Arunachal Pradesh.

Plum has assumed greater significance as fresh fruit and in processing industries. It is a delicious fruit prized both for its exquisite fresh fruit flavour and aroma. The fruits are 
fairly attractive but usually are soft, clingstone, round and heart shaped (Teskey el. 1978). The common plum ( $P$. domestica) is known for its diversity in fruit size, colour, flavour and is one of the most desirable plum species in terms of fruit quality (Gonez-Pleza and Ledbetter 2010). Plum species and cultivars are quite diverse in fruit characters such as fruit size, shape, colour, texture, aroma and quality depending on their climatic requirement and conditions. Newly introduced cultivars generally do not flourish well until and unless its performance and characterization is carried out simultaneously under the changing climatic conditions of their adaptation to new habitation and further recommended for commercial cultivation. This can be unrivalled through taxonomical studies, which could serve as an index for assigning correct status of a genotype.

The need of improving fruit quality is a priority for the modern plum culture under climate change scenario. The changes into plum culture completed with new varieties assessment and new research concerning the various phenological and physico-chemicals characteristics of the fruit according with the various ecological conditions. When growing the introduced plum cultivars, it is important to determine their characteristics in changing climatic scenario for their adaptation in local environment. Presently, Santa Rosa is the leading cultivar of plum in Himalayan states of Jammu and Kashmir and Himachal Pradesh, occupies about 75 per cent of the total under plum cultivation (Sundouri et al., 2017). But, the predominance of the single cultivar leads to the glut in the market as e result the farmers do not get remunerative price for their produce and sometimes even they do not get back the cost of production Hence, there is a need to have extended ripening period to avoid the glut in the market. This can be possible, if new exotic introductions are thoroughly studied under changing climatic conditions for their performance and recommendations.

Few exotic plum cultivars have been introduced at Central Institute of Temperate Horticulture, Srinagar with the objective to increase the germplasm base and their further recommendation for commercial cultivation. The information regarding the performance of these new introductions under the temperate condition of Kashmir is lacking though varieties exhibit tremendous variability in growth, yield and quality attributes. Area expansion under these new exotic varieties and to increase the total production of plums is possible only after proper evaluation of these exotic cultivars on various physico-chemical traits, yield and to designate them according to their maturity period. Hence the present study was undertaken to fill this gap.

\section{Materials and Methods}

The present investigation was carried out at Central Institute of Temperate Horticulture (CITH), Srinagar, Kashmir during the year 2014-15. Twelve-year-old bearing plum trees of different cultivars having uniform size and vigour were selected for study. The experimental Farm is situated at an altitude of 1588 meter above mean sea level with latitude of $34.8^{\prime}$ and longitude of $74.83^{\prime} \mathrm{N}$. The trees were spaced $5 \times 5$ meters in square system of planting and uniform cultural practices as per package and practices were followed during the period of study. The orchard soil was moderately deep with medium fertility status. Fourteen cultivars of plum presented in table 1 were evaluated for different traits. Single tree in each cultivar constituted an experimental unit and each cultivar was replicated three times.

Hard and firm ripe fruits were harvested from the experimental trees at physiological maturity during early hours in the morning. 
The fruit was immediately transferred to laboratory washed under running tap water, cleaned and dried with a piece of muslin cloth. Fruit length, fruit breadth, stone length and stone breadth was measured with digital Vernier's Calliper and expressed in mm. Fruit and stone weight was recorded on battery operated digital balance. Firmness of ten randomly selected fruits was measured with the help of a penetrometer (Model FT-327, USA) using $8 \mathrm{~mm}$ stainless steel probe and expressed in terms of $\mathrm{Kg} / \mathrm{cm}^{2}$. Solid soluble content (SSC) of juice were determined with the help of Erma hand refractometer in terms of degree Brix. Titratable acidity (TA) was calculated in terms of anhydrous malic acid by titrated against $0.1 \mathrm{~N} \mathrm{NaOH}$ solution using phenolphthalein as an indicator. Fruit juice $\mathrm{pH}$ (FPH) was measured with electronic $\mathrm{pH}$ electrode meter. The data recorded during the course of this study was analyzed statistically as per the procedures described by (Singh el al. 1973) and results are summarized in tables with average of three replications.

\section{Results and Discussion}

\section{Fruit characters}

Fruit length in different cultivars ranged from $30.0 \mathrm{~mm}$ to $50.42 \mathrm{~mm}$, fruit breadth from 28.62 to $47.70 \mathrm{~mm}$ and fruit thickness from 27.18 to $44.56 \mathrm{~mm}$. Maximum fruit length was measured in cultivar Grand Duke (50.42 mm) whereas minimum was observed in cultivar Krassivica Plum (30.0 mm). Maximum fruit breadth and fruit thickness was measured in cultivar Frontier $(47.70 \mathrm{~mm}$ and $44.56 \mathrm{~mm}$ ) whereas minimum fruit breadth was recorded in cultivar Krassivica Plum (28.62 $\mathrm{mm}$ and $27.18 \mathrm{~mm}$ ). Fruit weight under present study ranged from $26.44 \mathrm{~g}$ to $65.78 \mathrm{~g}$ in different plum cultivars. Maximum fruit weight $(65.78$ g) was recorded in cultivar Frontier followed by Grand Duke (53.34 g) and minimum fruit weight was recorded in cultivar Krassivica
Plum (26.44 g). This variation might be due to differences in genetic constitution of cultivars and crop load that appear to be responsible for difference in fruit weight and size. The results are in agreement to the findings of Ozakman et al., (1995) and Chanana et al., (1992) and Rouse and Sherman (1989) who reported that the cause of variation in fruit weight may be due to varied fruit size (length and breadth) and difference in crop load. The present findings are also in conformity with earlier studies conducted by Bal and Chohan (1981) and Mishra and Srivastava (1973). The variation in fruit breadth and thickness in peach and other Prunus species has also been reported by other workers (Chadha and Sankhayayan, 1974, Ladhar, 1978).

Fruit colour varied appreciably among the different plum cultivars. Red purple colour was possessed by five cultivars (Grand Duke, Black Amber, Au- Rosa, Kubio Plum and Krassivica Plum), red colour by five cultivars (Red Beaut, Tarrol, Burbank, Red Plum and Beauty), grey purple by Frontier and yellow colour by three cultivars viz; Au- Cherry, Kanto 5 and Monarch. Fruit flesh colour of different plum cultivars revealed that yellow orange colour was dominant with the traces of the other colours depending upon their genetic constitution and pigmentation. Yellow orange colour was found dominant in seven cultivars viz; Frontier, Red Beaut, Tarrol, Grand Duke, Red Plum, Burbank and Beauty, dark red flesh in cultivars Black Amber, Kubio Plum and Krassivica Plum, red flesh in cultivar Au-Rosa and yellow flesh in three cultivars viz; AuCherry, Kanto 5 and Monarch. Similar variations in the fruit and flesh colour have been reported by different workers (Singh et al., 2011, Kumar et al., 2013 and Tandon, 2006)

Present data revealed wide variation among the different plum cultivars for their fruit shape. Eight plum cultivars viz; Frontier, Red 
Beaut, Tarrol, Burbank, Kanto 5, Kubio Plum, Monarch and Beauty were round, cultivars Red Plum and Krassivica Plum were ovate, cultivars Black Amber and Au- Cherry were elliptic, cultivar Grand Duke was oblong however cultivar Au- Rosa had heart shape. Variation in fruit shape was also reported by other workers (Sharma, 1999 and Tandon, 2006), which might be due to difference in genetic makeup of these cultivars and variation in climate of the region.

\section{Stone characters}

Length and breadth of stone in different cultivars ranged from $10.58 \mathrm{~mm}$ (Red Plum) to $21.70 \mathrm{~mm}$ (Grand Duke) and $4.47 \mathrm{~mm}$ (Kanto 5) to $14.94 \mathrm{~mm}$ (Grand Duke), respectively. Stone weight ranged from $0.89 \mathrm{~g}$ to $1.84 \mathrm{~g}$ in studied cultivars. Highest stone weight was recorded in cultivar Grand Duke $(1.86 \mathrm{~g})$ and lowest was recorded in $\mathrm{Au}-$ Cherry and Kubio Plum (0.89 g). Maximum pulp: stone ratio was recorded in cultivar Kanto 5 (56.46) and the minimum pulp: stone ratio was recorded in cultivar Red Beaut (25.58).

Adherence of stone to the fruit flesh was categorized as cling, semi cling and free stone types. Among the different cultivars under investigation, nine cultivars (Red Beaut, Tarrol, Black Amber, Burbank, Au- Cherry, Kanto 5, Red Plum, Krassivica Plum and Monarch) were cling stone type, three cultivars (Frontier, Grand Duke and Au- Rosa) were free stone type and two cultivars (Kubio Plum and Beauty) were semi cling stone type.

Variation in pulp: stone ratio in plum has been reported by Thakur et al., (2014) and Josan et al., (1999). They found that pulp: stone ratio ranged from 59.13 per cent to 19.56 per cent. Variation in stone weight has been reported by Dhatt et al., (1992), Vukojevic et al., (2012) which ranged from $2.90 \mathrm{~g}$ in cultivar Fortune and $0.95 \mathrm{~g}$ in Red Beaut. The variation in pulp stone ratio depends on the fruit size and weight of the fruit. Higher pulp stone ratio in some cultivars may be due to higher fruit weight and less stone weight. The variability with respect to stone adherence in different plum cultivars might be due to varietal characteristics. Similar type of variation has also been reported by other workers (Singh et al., 2011, Sharma and Verma, 2012 and Tandon 2006).

\section{Chemical characters}

Fruit chemical characters of different plum cultivars such as total sugars, reducing sugar, non-reducing sugar, TSS, acidity, sugar acid ratio and juice $\mathrm{pH}$ was recorded under the present study. Maximum total sugars were recorded in cultivar Frontier (8.96 per cent) and minimum total sugars were recorded in cultivar Red Plum (5.41 per cent). Reducing sugar ranged from 3.88 per cent (Au-Rosa) to 6.98 per cent (Monarch) whereas nonreducing sugar ranged from 0.38 per cent (Red Plum) to 2.78 per cent (Tarrol) under present investigation.

Maximum total soluble solids (TSS) were recorded in cultivar $\mathrm{Au}$ - Rosa $\left(16.06^{\circ} \mathrm{B}\right)$ while the lowest was recorded in cultivar Krassivica Plum $\left(10.0^{\circ} \mathrm{B}\right)$. Fruit acidity of different plum cultivars ranged from 1.18 to $2.22 \%$. The maximum acidity was recorded in cultivar Black Amber (2.22 \%) and minimum acidity was recorded in cultivar Frontier (1.18\%). Maximum sugar: acid ratio was recorded in cultivar Frontier $(7.58 \%)$ and the minimum sugar: acid ratio was recorded in cultivar Burbank $(2.93 \%)$. The $\mathrm{pH}$ of juice was maximum in cultivar Monarch (4.2) and lowest in cultivar Beauty (3.1).

Significant differences in fruit juice $\mathrm{pH}$ among different cultivars and their parents was reported by Milosevic and Milosevic (2011) in 
plum and values ranged from 3.35 (Cacanska Lepotica) to 0.04 (Stanley). Similar type of variation in fruit juice $\mathrm{pH}$ in plum has also been reported by other workers (Nergiz and Yildiz, 2010, Tomas-Barberan et al., 2001). Sugar: acid ratio is an important factor in determining the consumer acceptability of any edible fruit. Variation in reducing and nonreducing sugar, TSS, acidity and $\mathrm{pH}$ of juice may be due to genetical makeup of plum cultivars (Erturk et al., 2009) and may also be affected by agro-climatic conditions, management practices, location and storage conditions (Josan et al., 1999) and Sharma (1994). The chemicals constitute of the different cultivars depends on the different rate of conversions of complex organic acids into simple sugars at the time of maturity and has been variated by the agro-climatic conditions and nutritional factors (Nergiz and Yildiez, 2010) (Table 2-4).

Table.1 Plum cultivars used in study

\begin{tabular}{|c|c|c|c|c|c|}
\hline Cultivar & Fruit colour & Flesh colour & Fruit shape & Maturity & $\begin{array}{c}\text { Stone } \\
\text { adherence }\end{array}$ \\
\hline Frontier & Grey purple & Yellow orange & Round & $2^{\text {nd }}$ June & Free stone \\
\hline Red Beaut & Red & Yellow orange & Round & $6^{\text {th }}$ June & Cling stone \\
\hline Tarrol & Red & Yellow orange & Round & $2^{\text {nd }}$ June & Cling stone \\
\hline Grand Duke & Red purple & Yellow orange & Oblong & $26^{\text {th }}$ June & Free stone \\
\hline Black Amber & Red purple & Dark red & Elliptic & $7^{\text {th }}$ June & Cling stone \\
\hline Burbank & Red & Yellow orange & Round & $10^{\text {th }}$ June & Cling stone \\
\hline Au-Cherry & Yellow & Yellow & Elliptic & $5^{\text {th }}$ June & Cling stone \\
\hline Au-Rosa & Red purple & Red & Heart shape & $2^{\text {nd }}$ June & Free stone \\
\hline Kanto 5 & Yellow & Yellow & Round & $12^{\text {th }}$ June & Cling stone \\
\hline Kubio Plum & Red purple & Dark red & Round & $20^{\text {th }}$ June & $\begin{array}{l}\text { Semi cling } \\
\text { stone }\end{array}$ \\
\hline Red Plum & Red & Yellow orange & Ovate & $28^{\text {th }}$ May & Cling stone \\
\hline Krassivica Plum & Red purple & Dark red & Ovate & $5^{\text {th }}$ June & Cling stone \\
\hline Monarch & Yellow & Yellow & Round & $8^{\text {th }}$ June & Cling stone \\
\hline Beauty & Red & Yellow orange & Round & $9^{\text {th }}$ June & $\begin{array}{l}\text { Semi cling } \\
\text { stone }\end{array}$ \\
\hline
\end{tabular}


Table.2 Qualitative characters of plum cultivars

\begin{tabular}{|c|c|c|c|c|c|c|c|c|c|}
\hline Cultivar & $\begin{array}{l}\text { Fruit } \\
\text { weight } \\
\text { (g) }\end{array}$ & $\begin{array}{l}\text { Fruit } \\
\text { length } \\
\text { (mm) }\end{array}$ & $\begin{array}{l}\text { Fruit } \\
\text { breadth } \\
\text { (mm) }\end{array}$ & $\begin{array}{c}\text { Fruit } \\
\text { thickness } \\
\text { (mm) }\end{array}$ & $\begin{array}{c}\text { Yield/ } \\
\text { tree } \\
\text { (kg) }\end{array}$ & $\begin{array}{l}\text { Stone } \\
\text { length } \\
(\mathrm{mm})\end{array}$ & $\begin{array}{c}\text { Stone } \\
\text { breadth } \\
(\mathrm{mm})\end{array}$ & $\begin{array}{l}\text { Stone } \\
\text { weight } \\
\text { (g) }\end{array}$ & $\begin{array}{c}\text { Pulp : } \\
\text { stone ratio } \\
(\%)\end{array}$ \\
\hline Frontier & 65.78 & 50.02 & 47.70 & 44.56 & 52.54 & 12.82 & 6.44 & 1.48 & 43.44 \\
\hline Red Beaut & 48.91 & 46.72 & 44.28 & 38.67 & 32.24 & 12.73 & 10.80 & 1.84 & 25.58 \\
\hline Tarrol & 42.40 & 33.70 & 29.86 & 27.44 & 35.00 & 14.66 & 6.13 & 1.31 & 31.36 \\
\hline Grand Duke & 53.34 & 50.42 & 47.00 & 44.22 & 42.49 & 21.70 & 14.94 & 1.86 & 27.67 \\
\hline Black Amber & 34.82 & 30.85 & 30.57 & 28.85 & 22.66 & 14.59 & 10.76 & 1.00 & 33.82 \\
\hline Burbank & 46.11 & 43.30 & 38.23 & 35.44 & 35.18 & 14.64 & 10.93 & 1.16 & 38.75 \\
\hline Au-Cherry & 44.61 & 35.89 & 42.49 & 38.36 & 44.13 & 12.91 & 6.62 & 0.89 & 49.12 \\
\hline Au-Rosa & 38.92 & 46.00 & 35.07 & 31.09 & 22.95 & 15.00 & 5.64 & 1.17 & 32.26 \\
\hline Kanto 5 & 51.72 & 30.45 & 30.97 & 27.70 & 40.35 & 11.88 & 4.87 & 0.90 & 56.46 \\
\hline Kubio Plum & 28.45 & 32.28 & 30.99 & 27.48 & 18.07 & 11.35 & 7.47 & 0.89 & 30.96 \\
\hline Red Plum & 36.56 & 38.44 & 32.93 & 28.95 & 30.57 & 10.58 & 7.82 & 1.18 & 29.98 \\
\hline Krassivica Plum & 26.44 & 30.00 & 28.62 & 27.18 & 26.56 & 12.15 & 6.99 & 0.94 & 27.12 \\
\hline Monarch & 44.87 & 43.32 & 40.97 & 36.85 & 37.55 & 15.71 & 7.18 & 1.52 & 28.51 \\
\hline Beauty & 47.65 & 43.44 & 40.58 & 38.39 & 45.31 & 12.86 & 5.97 & 1.22 & 38.05 \\
\hline Mean & 43.61 & 39.63 & 37.16 & 33.94 & 34.68 & 13.82 & 8.04 & 1.24 & 35.22 \\
\hline $\mathrm{CD}_{0.05}$ & 1.17 & 0.88 & 2.21 & 1.30 & 1.43 & 0.31 & 0.36 & 0.50 & 0.82 \\
\hline $\mathrm{CV}$ & 10.23 & 7.36 & 11.33 & 5.52 & 5.54 & 11.31 & 7.19 & 2.12 & 9.26 \\
\hline
\end{tabular}


Table.3 Quantitative characters of plum cultivars

\begin{tabular}{|c|c|c|c|c|c|c|c|}
\hline Cultivar & $\begin{array}{l}\text { Total } \\
\text { sugars } \\
(\%)\end{array}$ & $\begin{array}{c}\text { Reducing } \\
\text { sugars } \\
(\%)\end{array}$ & $\begin{array}{l}\text { Non- reducing } \\
\text { sugars } \\
(\%)\end{array}$ & $\begin{array}{l}\text { TSS } \\
(\%)\end{array}$ & $\begin{array}{c}\text { Acidity } \\
(\%)\end{array}$ & $\begin{array}{l}\text { Sugar: } \\
\text { acid ratio }\end{array}$ & $\begin{array}{c}\text { Juice } \\
\text { pH }\end{array}$ \\
\hline Frontier & 8.96 & 6.64 & 2.20 & 14.86 & 1.18 & 7.59 & 3.7 \\
\hline Red Beaut & 6.89 & 5.31 & 1.50 & 14.03 & 1.49 & 4.62 & 3.7 \\
\hline Tarrol & 8.44 & 5.45 & 2.78 & 15.13 & 1.32 & 6.39 & 3.6 \\
\hline Grand Duke & 7.66 & 5.19 & 2.34 & 11.23 & 1.69 & 4.53 & 3.9 \\
\hline Black Amber & 8.67 & 5.86 & 2.66 & 10.60 & 2.22 & 3.90 & 3.7 \\
\hline Burbank & 6.17 & 4.54 & 1.54 & 13.03 & 2.10 & 2.93 & 4.0 \\
\hline Au-Cherry & 7.63 & 6.59 & 0.98 & 11.80 & 2.20 & 3.46 & 4.1 \\
\hline Au-Rosa & 5.67 & 3.88 & 1.70 & 16.06 & 1.29 & 4.29 & 3.6 \\
\hline Kanto 5 & 7.84 & 4.95 & 2.77 & 14.80 & 1.83 & 4.28 & 3.7 \\
\hline Kubio Plum & 8.05 & 5.58 & 2.34 & 10.60 & 1.38 & 5.83 & 3.3 \\
\hline Red Plum & 5.41 & 5.37 & 0.38 & 11.70 & 1.32 & 4.09 & 3.3 \\
\hline Krassivica Plum & 8.41 & 6.36 & 1.94 & 10.00 & 1.65 & 5.09 & 4.1 \\
\hline Monarch & 8.20 & 6.98 & 1.15 & 15.06 & 1.75 & 4.68 & 4.2 \\
\hline Beauty & 7.17 & 5.55 & 1.53 & 13.06 & 1.31 & 5.47 & 3.1 \\
\hline Mean & 7.51 & 5.31 & 1.82 & 12.56 & 1.66 & 4.35 & 3.40 \\
\hline $\mathrm{CD}_{0.05}$ & 0.62 & 0.09 & 0.34 & 1.30 & 0.29 & 0.06 & 0.25 \\
\hline CV & 5.23 & 10.05 & 10.92 & 5.97 & 10.51 & 7.76 & 4.08 \\
\hline
\end{tabular}

Table.4 Physico-chemical characteristics of plum cultivars

\begin{tabular}{|c|c|c|c|c|c|c|c|}
\hline Cultivar & $\begin{array}{l}\text { Total } \\
\text { sugars } \\
(\%)\end{array}$ & $\begin{array}{c}\text { Reducing } \\
\text { sugars } \\
(\%)\end{array}$ & $\begin{array}{l}\text { Non- reducing } \\
\text { sugars } \\
(\%)\end{array}$ & $\begin{array}{l}\text { TSS } \\
(\%)\end{array}$ & $\begin{array}{c}\text { Acidity } \\
(\%)\end{array}$ & $\begin{array}{l}\text { Sugar: } \\
\text { acid ratio }\end{array}$ & $\begin{array}{c}\text { Juice } \\
\text { pH }\end{array}$ \\
\hline Frontier & 8.96 & 6.64 & 2.20 & 14.86 & 1.18 & 7.59 & 3.7 \\
\hline Red Beaut & 6.89 & 5.31 & 1.50 & 14.03 & 1.49 & 4.62 & 3.7 \\
\hline Tarrol & 8.44 & 5.45 & 2.78 & 15.13 & 1.32 & 6.39 & 3.6 \\
\hline Grand Duke & 7.66 & 5.19 & 2.34 & 11.23 & 1.69 & 4.53 & 3.9 \\
\hline Black Amber & 8.67 & 5.86 & 2.66 & 10.60 & 2.22 & 3.90 & 3.7 \\
\hline Burbank & 6.17 & 4.54 & 1.54 & 13.03 & 2.10 & 2.93 & 4.0 \\
\hline Au-Cherry & 7.63 & 6.59 & 0.98 & 11.80 & 2.20 & 3.46 & 4.1 \\
\hline Au-Rosa & 5.67 & 3.88 & 1.70 & 16.06 & 1.29 & 4.29 & 3.6 \\
\hline Kanto 5 & 7.84 & 4.95 & 2.77 & 14.80 & 1.83 & 4.28 & 3.7 \\
\hline Kubio Plum & 8.05 & 5.58 & 2.34 & 10.60 & 1.38 & 5.83 & 3.3 \\
\hline Red Plum & 5.41 & 5.37 & 0.38 & 11.70 & 1.32 & 4.09 & 3.3 \\
\hline Krassivica Plum & 8.41 & 6.36 & 1.94 & 10.00 & 1.65 & 5.09 & 4.1 \\
\hline Monarch & 8.20 & 6.98 & 1.15 & 15.06 & 1.75 & 4.68 & 4.2 \\
\hline Beauty & 7.17 & 5.55 & 1.53 & 13.06 & 1.31 & 5.47 & 3.1 \\
\hline Mean & 7.51 & 5.31 & 1.82 & 12.56 & 1.66 & 4.35 & 3.40 \\
\hline $\mathrm{CD}_{0.05}$ & 0.62 & 0.09 & 0.34 & 1.30 & 0.29 & 0.06 & 0.25 \\
\hline $\mathrm{CV}$ & 5.23 & 10.05 & 10.92 & 5.97 & 10.51 & 7.76 & 4.08 \\
\hline
\end{tabular}


Fig.1 Variability in fruit shape, size and colour of plum cultivars under study
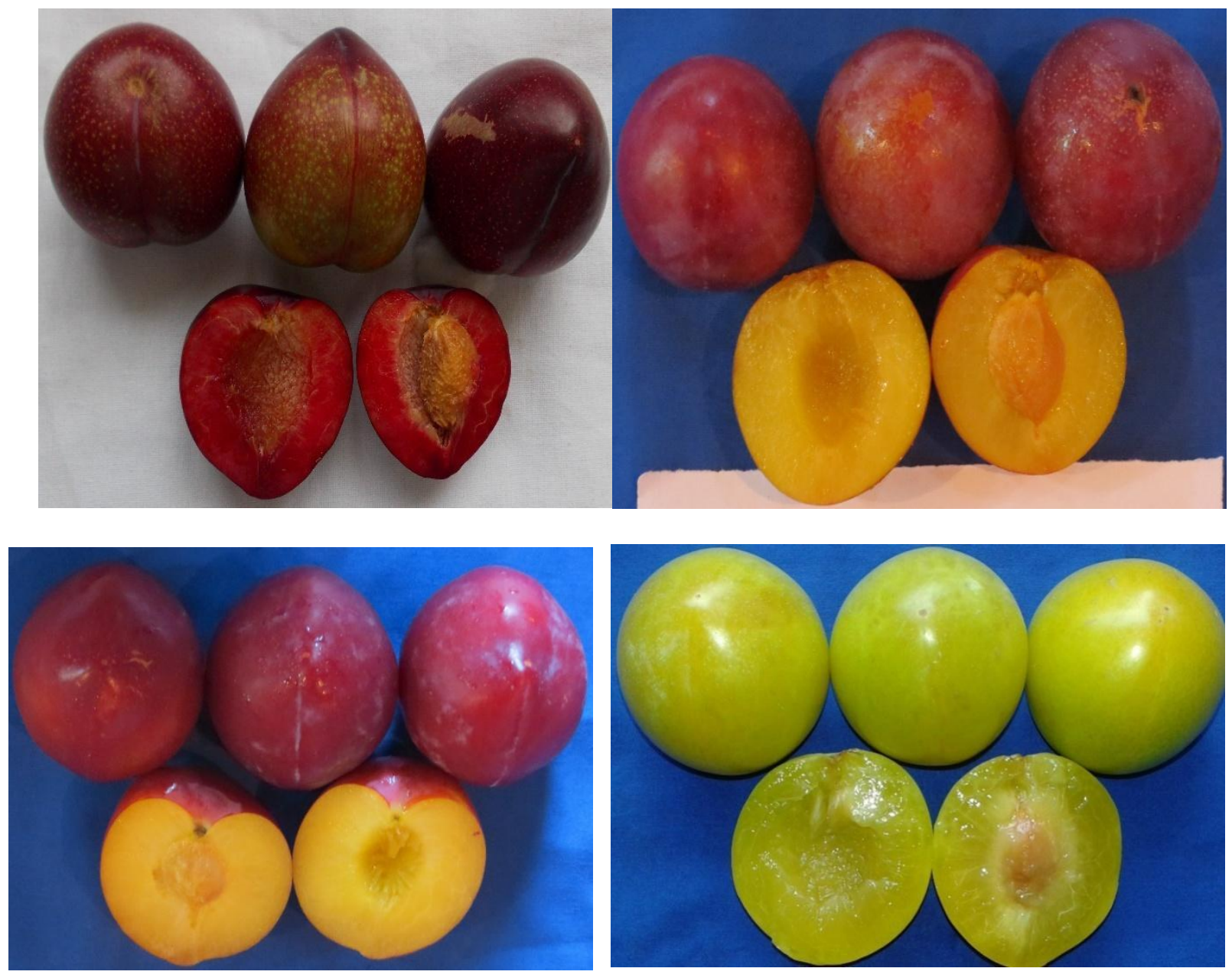

Legend: A- Heart

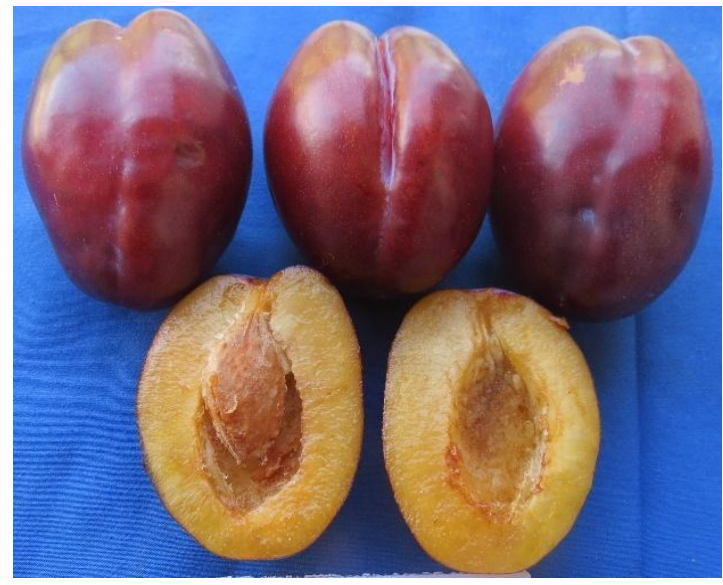

\section{B- Elliptic Shape; \\ C- Oblong Shape; \\ D- Round Shape; \\ E- Ovate Shape}

Shape; 


\section{Yield}

In the present study, fruit maturity was earliest in cultivar Red Plum ( $28^{\text {th }}$ May) and late in cultivar Grand Duke ( $26^{\text {th }}$ June). The yield per tree in different cultivars ranged from $18.07 \mathrm{~kg}$ to $52.54 \mathrm{~kg}$. The maximum yield per tree was recorded in cultivar Frontier $(52.54 \mathrm{~kg})$ and minimum yield was recorded in cultivar Kubio Plum (18.07 kg). The time of maturity of plum cultivars ranged from the middle of June to the first week of September Balik (2004) and Sharma and Jason (1993). These different findings are most likely attributed to the characteristics of different species of fruit. Further, the differences in fruit maturity may also be the result of different ecological conditions.

The yield potential of a plum crop is inherently dependent upon their adaptation to agro-climatic conditions and management practices. The ultimate objective of the grower is to have high yield, which is highly variable among the different cultivars and is genetically controlled. However, yield generally depends on the health of tree, nutrition, age of plants, cultural practices adopted, pest and disease incidence and finally climatic conditions of cultivated area (Balik (2004).

It is concluded, on the basis of various physicchemical characteristics as well as yield, the cultivar 'Frontier' was found to be the best, whereas, Au-Rosa was best with respect to sweetness of fruit. Cultivars viz; 'Frontier', 'Grand Duke' and 'Au- Rosa' were free stone. On the basis of harvesting date, all the cultivars under study were grouped into early (last week of May), mid (third week of June) and late (last week of June) cultivar. Cultivars viz; Red Plum, Frontier, Tarrol and Au-Rosa were early, Red Beaut, Monarch, Beauty, Krassivica Plum, Black Amber, Au-Cherry and Burbank were mid season and Grande
Duke, Kento-5 and Kubio Plum were late to harvest. The cultivar with distinct superiority in yield and quality characteristics were recommended for commercial adaption and in further improvement programmes through breeding.

\section{References}

Bal, J.S. and Chohan, G.S. 1981. Biochemical changes in development of Flordasun peach. Indian Food Packer 35: 46-50.

Balik, S. 2004. Studies on new table Japanese Plum (Prunus salicina Lind.) cultivars growing for export in Kahramanmaras. M.Sc. Thesis submitted to Institute of Natural Science, University of Kahramanmaras, Turkey 74: 137-142.

Chadha, T.R. and Sankhyayan, S.A. 1974. Trees and fruit characters of some promising peach cultivars grown in Himachal Pradesh. Progressive Horticulture 6: 41-48.

Chanana, Y.R, Nijjar, G.S., Kanwar, J.S., Kaundal, G.S., Brar, S.S. and Deol, I. S. 1992. Studies on the performance of a new peach cultivars suitable for sub-tropics. Indian Journal of Horticulture 49: 37-39.

Dhatt, A.S., Chanana, Y.R., Minnas, P.P.S. and Bindra, A.S. 1992. Table plum Fla. 1-2. Indian Horticulture 37: 41.

Erturk, Y., Ercisli, S. and Tosun, M. 2009. Physico chemical characteristics of wild plum fruits (Prunus spinosa L.). International Journal of Plant Production 3: 89-92.

Gonez-Pleza, E. and Ledbetter, C. 2010. Handbook of fruits, vegetables and flowers: In: Y.H. Hui (ed), John Wiley \& sons Inc. pp. 10-45.

Josan, J.S., Sharma, J.N., Mehrotra, N.K. and Monga, P.K. 1999. Performance of some plum cultivars under aridirrigated region of Punjab. Indian 
Journal of Horticulture 56: 299-303.

Kumar, K., Sonali, T., Dinesh, S. and Vikas, K. S. 2013. Evaluation of promising Japanese plum genotypes for mid-hills of Himachal Pradesh. Indian Journal of Horticulture 70(2): 283-286.

Ladhar, D.S. 1978. Studies on the maturity and ripening of peach. M.Sc. Thesis submitted to Department of Pomology PAU, Ludhiana, India.

Milosevic, T. and Milosevic, N. 2012. Phenotypic diversity of autochthonous European (Prunus domestica L.) and Damson (Prunus insititia L.) plum accessions based on multivariate analysis. Horticultural Science 39(1): 8-20.

Mishra, R.S. and Srivastava, R.P. 1973. Some important commercial varieties of peach grown in the hills of U.P. Progressive Horticulture 4: 126-36.

Mishra, R.S. and Srivastava, R.P. 1973. Some important commercial varieties of peach grown in the hills of U.P. Progressive Horticulture 4: 126-36.

Nergiz, C. and Yildiez, H. 2010. Research on chemical composition of some varieties of European plums adapted to the Aegean district of Turkey. Journal of Agriculture Food Chemistry 45: 2820-2823.

Ozakman, S., Onal, K., Ozkarakas, I. and Gonulsen, N. 1995. Studies on the determination of suitable Japan plum (Prunus salicina Lind.) cultivars for the Aegean Region. 2nd Turkish Nat. Hortic. Congress 1: 194-198.

Rouse, R.E. and Sherman, W.B. 1989. Tropic Beauty: A low chilling peach for subtropical climates. Horticultural Science 24: 165-66.

Sharma, J.N. and Josan, J. S. 1993. Varietal performance of plum under arid irrigated region of Punjab. Indian Journal of Horticulture 50(4):301-305.

Sharma, S.D. 1994. Variation in local apricot growing in district Kinnaur of Himachal Pradesh (India). Fruit Varieties Journal 48: 225-228.

Sharma, S.K. and Verma, K.S. 2012. Adaptation potential of low chill peach varieties to inter-annual climatic variability in the lower shiwalik Himalayas. International Journal of Agriculture, Environment and Biotechnology 7(1): 157-164.

Sharma, V. K. 1999. Studies on flowering, pollination and fruit characteristics in some plum cultivars. MSc. Thesis submitted to Department of Fruit Science, Dr. YS Parmar University of Horticulture and Forestry, Nauni, Solan Himachal Pradesh, India.

Singh, D., Sharma, V.K. and Kumar, K. 2011. Evaluation and characterization of some exotic plum germplasm accessions for fruit quality traits. Journal of Hill Agriculture 2(1): 5962.

Singh, G., Sharma, K.K. and Jawanda, J.S. 1973. Evaluation of peach cultivars for the arid zone of the Punjab. Journal of Research 18: 13-17.

Sundouri, A.S., Verma, S. K., Sharma, M. K., Kumar Amit, Nowsheen N., and Khalil A. 2017. Characterization of newly introduced exotic plum cultivars for character association and genetic improvement. Current Journal of Applied Science and Technology. 24(2): 1-10.

Teskey, J.E. and Shoemaker, J.S. 1978. Peach. In: Tree Fruit Production. AVI Publications, Westport, Connecticut, Ireland. pp. 187-201.

Thakur, G., Sharma, Lata, S. and Yadav, A. 2014. Floral and physico-chemical characters of Japanese plum (Prunus salicina Lindl.) cultivars. Journal Research Punjab Agriculture University 51(1): 36-41.

Tomas-Barberan, F.A., Gil, M.I., Cremin, P., 
Waterhouse, A.L., Hess-Pierce, B. and Kader, A.A. 2001. HPLC-DADESIMS analysis of plum, peach and nectarines. Journal of Agricultural Food Chemistry 49: 4748-60.

Tondon, S. 2006. Studies on evaluation of some apricot, peach and plum introductions. M.Sc. Thesis submitted to Department of Fruit Science, Dr. YS Parmar University of Horticulture and Forestry, Nauni, Solan, Himachal Pradesh, India.

Vishnu, F. Botu, I. and Bacin, A. 2012.
Assessment of production of capacity for some plum, myrobalan and sloe cultivars and selections grown in northern Olteric. Acta Horticulturae 968: 75-80.

Vukojevic, D., Simic, J., Dragisic, N., Sevo, D., Misimovic, M., Zavisic, N., Bolic, E. and Radanovic, B. 2012. Evaluation of the quality of autochthonous plum cultivars in the area of Bosanski Petrovac. Third International Scientific Symposium "Agrosym Jahorina" pp. 161-65.

\section{How to cite this article:}

Sundouri, A.S., S.K. Verma, M.K. Sharma, S.A. Simnani, Aroosa Khalil, Nowsheen Nazir and Rafiya Mushtaq. 2018. Varietal Characteristics of Exotic Plum Cultivars under Changing Climate Scenario of North Western Himalayas. Int.J.Curr.Microbiol.App.Sci. 7(07): 33893399. doi: https://doi.org/10.20546/ijcmas.2018.707.394 